\title{
Structural and Electronic Characterization of Nanocrystalline Diamond-Like Carbon Thin Films
}

Neeraj Dwivedia, ${ }^{a, b}$ Sushil Kumar, ${ }^{a}$, R. K. Tripathi ${ }^{a}$, J. D. Carey ${ }^{c}$, Hitendra K. Malik ${ }^{b}$ and M. K. Dalai $^{\mathrm{a}}$

${ }^{a}$ National Physical Laboratory (CSIR), K.S. Krishnan Road, New Delhi - 110 012, India,

${ }^{b}$ Department of Physics, Indian Institute of Technology Delhi, New Delhi-110016, India,

${ }^{c}$ Advanced Technology Institute, University of Surrey, Guildford, GU2 7XH, Surrey, United Kingdom

\begin{abstract}
The origin of low threshold field emission (threshold field $1.25 \mathrm{~V} / \mu \mathrm{m}$ ) in nanocrystalline diamond-like carbon (nc-DLC) thin films is examined. The introduction of nitrogen and thermal annealing are both observed to change the threshold field and these changes are correlated with changes to the film microstructure. A range of different techniques including micro-Raman and infrared spectroscopy, X-ray diffraction, electron microscopy, energy dispersive X-ray analysis and time of flight-secondary ion mass spectroscopy are used to examine the properties of the films. A comparison of the field emission properties of nc-DLC films with atomically smooth amorphous DLC (a-DLC) films reveals that nc-DLC films have lower threshold fields. Our results show that nc-DLC can be a good candidate for large area field emission display panels and cold cathode emission devices.
\end{abstract}

Keywords: diamond-like carbon, carbon nanostructures, field emission, threshold field, Raman spectroscopy, electron microscopy

*Corresponding Author. Tel.: +91 11 45608650; Fax: +91 1145609310.

E-mail address: skumar@nplindia.org (Sushil Kumar) 


\section{INTRODUCTION}

Carbon based materials have a number of properties that are attractive for large area electronic applications. ${ }^{1-6}$ For example, diamond-like carbon can be deposited over large areas and at low substrate temperatures. ${ }^{5}$ An important electronic property of such carbon based materials, which includes diamond, carbon nanotubes (CNT) and CNT-composites, is their ready ability to emit electrons into vacuum which make them suitable for applications in field emission display technology., 2,8 Diamond-like carbon (DLC) thin films are well known for their exceptional mechanical properties ${ }^{9-14}$ and recently, we have explored the mechanical, optical and electrical properties of DLC and modified DLC thin films. ${ }^{15-19}$ DLC thin films are known to emit electrons $^{20,21}$, however, compared with diamond and CNTs, their threshold field $\left(\mathrm{E}_{\mathrm{T}}\right)$ tends to be higher and emission current $\left(\mathrm{I}_{\mathrm{E}}\right)$ is lower. As a consequence for the past few years research has been focused on nanocrystalline DLC (nc-DLC) films in order to reduce $\mathrm{E}_{\mathrm{T}}$ and enhance $\mathrm{I}_{\mathrm{E}}$. If the value of $\mathrm{E}_{\mathrm{T}}$ found in DLC and nc-DLC thin films could be engineered to be comparable to that of CNTs this will be a major breakthrough for field emission based devices as the deposition of DLC and nc-DLC thin films over large area is a relatively simple and inexpensive process.

At present the values of $E_{T}$ reported from $C N T$ cathodes vary from $1 \mathrm{~V} / \mu \mathrm{m}$ to 5 $\mathrm{V} / \mu \mathrm{m} .{ }^{2,6,7}$, whereas $\mathrm{E}_{\mathrm{T}}$ normally starts beyond $5 \mathrm{~V} / \mu \mathrm{m}$ and can reach above $20 \mathrm{~V} / \mu \mathrm{m}$ for DLC, tetrahedral amorphous carbon and nano-diamond thin films. ${ }^{20-22}$ Ikeda and Teii ${ }^{23}$ have demonstrated a low value of $\mathrm{E}_{\mathrm{T}}$ of $3 \mathrm{~V} / \mu \mathrm{m}$ in a nanocrystalline diamond field emitter. However, further reductions in $\mathrm{E}_{\mathrm{T}}$ below $3 \mathrm{~V} / \mu \mathrm{m}$ in DLC, modified DLC and nano-diamond films will be a great achievement towards the realization of simple, cheap and efficient field emission devices. In this paper, low threshold field emission $\left(\mathrm{E}_{\mathrm{T}} \sim 1.25 \mathrm{~V} / \mu \mathrm{m}\right)$ of electrons in simply fabricated nanocrystalline DLC (nc-DLC) films is demonstrated. In addition, the influence of nitrogen and vacuum annealing on the properties of modified nc-DLC thin films is also studied. The field 
emission characteristics of comparatively higher self-bias grown amorphous DLC (a-DLC) and nitrogen incorporated amorphous DLC (a-DLC:N) films are also studied and compared with the as grown and modified nc-DLC thin films.

\section{MATERIALS AND METHODS}

2.1 Samples Preparation. Radio frequency (13.56 MHz) plasma enhanced chemical vapor deposition (RF-PECVD) is used for depositing the nanocrystalline diamond-like carbon (nc-DLC) and nitrogen incorporated nanocrystalline diamond-like carbon (nc-DLC:N) thin films over cleaned n-type silicon ( $\mathrm{Si}$ ) substrates at a base pressure of $10^{-5}$ Torr. The nc-DLC film is grown at a self-bias of $-100 \mathrm{~V}$ (sample EA-1) by maintaining a working pressure of $2.4 \times 10^{-3}$ Torr. This working pressure is obtained by first incorporating acetylene $\left(\mathrm{C}_{2} \mathrm{H}_{2}\right)$ gas that changes the pressure from $10^{-5}$ Torr to $7.5 \times 10^{-4}$ Torr and then argon (Ar) gas that changes the pressure from $7.5 \times 10^{-4}$ Torr to $2.4 \times 10^{-3}$ Torr. The nc-DLC: $\mathrm{N}$ thin film is deposited at a self-bias of -100 $\mathrm{V}$ (sample EA-2) with at a working pressure of $2.4 \times 10^{-3}$ Torr, obtained by incorporating $\mathrm{C}_{2} \mathrm{H}_{2}$ and nitrogen $\left(\mathrm{N}_{2}\right)$ gases. Samples EA-3 and EA-5 are obtained when sample EA-1 is annealed in a vacuum better than $10^{-5}$ Torr at $150^{\circ} \mathrm{C}$ and $250^{\circ} \mathrm{C}$, respectively, for $90 \mathrm{~min}$. Samples EA-4 and EA-6 are obtained when sample EA-2 is annealed at $150^{\circ} \mathrm{C}$ and $250^{\circ} \mathrm{C}$, respectively, for 90 min. Besides nc-DLC films, amorphous DLC (a-DLC) and nitrogen incorporated a-DLC (a-DLC:N) films are also fabricated at comparatively higher self-bias of $-180 \mathrm{~V}$ at a working pressure of 2.4 $\mathrm{x} 10^{-3}$ Torr. The a-DLC and a-DLC:N films grown at $-180 \mathrm{~V}$ are labeled as samples EA-9 and EA-10, respectively.

2.2 Characterization of Samples. All of the films are characterized for their morphological, structural and field emission properties by field emission-scanning electron microscopy (FE-SEM) (FEI QUANTA 200 F), Raman spectroscopy (Reinshaw inVia Reflex 
micron Raman spectrometer attached with air cooled argon ion laser), X-ray diffraction (XRD) (Rigaku Miniflex II), Fourier transform infrared (FTIR) spectroscopy (Perkin Elmer Spectrum BX), time of flight secondary ion mass spectroscopy (ToF-SIMS) (TOF-SIMS 5 of ION-TOF GmBH, Germany), Energy dispersive X-ray analysis (EDAX) and a Keithley software controlled I-V measurement unit (Keithley 2410), respectively. In addition, the optical and mechanical properties of the deposited films are investigated using ultra-violet spectroscopy (Shimadzu spectrophotometer) and nanoindentation (IBIS nanoindentation, M/S Fisher-Cripps laboratory, Australia), respectively. The field emission measurements are carried out at base pressure of $3 \mathrm{x}$ $10^{-7}$ Torr. The threshold field is defined as the applied field at which an emission current of $\sim 5 \mathrm{x}$ $10^{-7} \mathrm{~A}$ is obtained. The micro-Raman measurements are performed using excitation wavelength of visible range $(514.5 \mathrm{~nm})$. ToF-SIMS measurements are conducted at ultrahigh vacuum condition with $5 \times 10^{-10}$ mbar pressure, where pulsed primary ions from a $25 \mathrm{keV}$ Bi liquid-metal ion gun (LMIG) are used to bombard the sample surface to create secondary ions. The sputtering is done using a $500 \mathrm{eV} \mathrm{O}_{2}$ source to remove the first few layers from the sample surface. The sputtering and analysis area is $200 \times 200 \mu^{2}$ and $70 \times 70 \mu \mathrm{m}^{2}$, respectively for all the samples. The overall resolution for ToF-SIMS is $1 \mathrm{~nm}$.

\section{RESULTS AND DISCUSSION}

Figures 1(a)-1(c) show the FE-SEM images of samples EA-1, EA-2 and EA-5, respectively. The microscope images reveal nanostructured morphology with a uniform distribution of nanostructured carbon throughout the surface. A highly dense tightly-packed structure is found in sample EA-1. However, when nitrogen introduction and annealing at $250^{\circ} \mathrm{C}$ for 90 min of sample EA-1 are performed, slight changes into the structure of samples EA-2 and EA-5, respectively. FE-SEM images of samples EA-2 and EA-5 clearly reveal the formation of 
nanocrystalline but images show no significant chages in the structure. The FESEM image of the a-DLC film (sample EA-9, Fig. 1(d)), clearly confirms the amorphous morphology in that sample grown at higher self-bias.

The structural analysis of these samples is conducted using XRD with the recorded XRD patterns of samples EA-1 and EA-2 shown in Figs. 2(a) and 2(b), respectively. The XRD spectra clearly reveal a mixture of nanocrystalline and amorphous carbon due to the presence of several sharp peaks as well as a broad band in the range of $10^{\circ}-60^{\circ}$. The peaks which appear in the range from $40^{\circ}$ to $60^{\circ}$ in sample EA-1 correspond to various reflections of the $\mathrm{sp}^{3}$ diamond phase. Generally, nanodiamond films show a sharp and high intense diamond $<111\rangle$ peak at $43.9^{\circ}$. In contrast, sample EA-1 exhibits three peaks at $42.2^{\circ}, 45^{\circ}$ and $46.6^{\circ}$, which are close to peak $43.9^{\circ}$. We expect that sample may have significant strain and these peaks are appeared as a consequence of strain induced spliting of <111> peak. The peak obtained at $53.6^{\circ}$ also correspond to a diamond reflection. ${ }^{24}$ The sharp peaks at $28.4^{\circ}, 31.1^{\circ}, 34.9^{\circ}, 47.6^{\circ}$ and $56.4^{\circ}$ are attributed to the silicon substrate. ${ }^{24}$ The sharp peak generated at $38.4^{\circ}$ may arise from $\mathrm{SiC}<102>$, which comes from a contribution of $\mathrm{Si}$ and $\mathrm{C}$ both at the interface. ${ }^{24}$ Between $20^{\circ}-30^{\circ}$ the peaks are attributed to various reflections of $\mathrm{sp}^{2}$ bonded graphitic material. A very sharp peak appeared at $26.6^{\circ}$ corresponds to graphite $\left\langle 111>\right.$. A broad band is seen centered around $22^{\circ}$, which shows the amorphous structure of the carbon bonding. In sample EA-2, all these peaks are slightly shifted to higher $2 \theta$ side due to nitrogen induced modification. This sample show sharp peaks at $27^{\circ}, 28.7^{\circ}, 31.4^{\circ}, 35.2^{\circ}, 38.6^{\circ}, 41.4^{\circ}, 42.4^{\circ}, 45.4^{\circ}, 46.7^{\circ}, 47.7^{\circ}$ and $53.7^{\circ}$. Looking at the extra peak $41.4^{\circ}$; the peak at $42.4^{\circ}$ in EA-1 splits into two peaks at $41.4^{\circ}$ and $42.4^{\circ}$ in EA-2 attributed to nitrogen induced modification. It is to be noted that the intensity of the $\mathrm{sp}^{2}$ bonded band generated in the range $20^{\circ}-30^{\circ}$ is found to be comparatively less intense and $\mathrm{sp}^{3}$ bonded diamond peaks originated in the range $40^{\circ}-60^{\circ}$ are found to be comparatively more intense in sample EA-1 
than in sample EA-2. This suggests that sample EA-2 may have more $\mathrm{sp}^{2}$ phase owing to nitrogen introduction. Furthermore, an XRD spectrum of sample EA-9 is also recorded (not given here) that clearly confirms the creation of amorphous structure in this sample.

ToF-SIMS is a high resolution destructive technique by which not only the constituents of films can be investigated but also atomic diffusion at the film/substrate interface can be visualized. Figures 3(a)-3(d) show the ToF-SIMS depth profiling of samples EA-1, EA-2, EA-5 and EA-6. It can be seen that $\mathrm{C}$ and $\mathrm{H}$ are found to be main constituents of samples EA-1 and EA-5, whereas $\mathrm{C}, \mathrm{H}$ and $\mathrm{N}$ are found to be main constituents of samples EA-2 and EA-6, which agrees with our deposition parameters. An intense peak corresponding to the Si substrate is evident in all four spectra. It is important to note that no oxygen appears in the film region, as the presence of oxygen is recorded only when depth profiling of substrate region begins. The presence of oxygen in the $\mathrm{Si}$ substrate is attributed to the fact that Czochralski $(\mathrm{Cz})-\mathrm{Si}$ wafer possesses oxygen as an impurity. The depth profile gives clear elemental demarcation between $\mathrm{C}, \mathrm{H}$ and $\mathrm{Si}$ in case of samples EA-1 and EA-5 whereas $\mathrm{C}, \mathrm{H}, \mathrm{N}$ and $\mathrm{Si}$ in case of samples EA-2 and EA-6. This can be seen in sample EA-1 where C and $\mathrm{H}$ diffuse slightly into the Si substrate but that $\mathrm{H}$ diffuses deeper owing to its lower atomic weight. It is worth noting that the diffusion of $\mathrm{C}$ in sample EA-1 is found to be significantly lower than in unhydrogenated DLC and tetrahedral amorphous carbon (ta-C) films owing to presence of $\mathrm{H}$. Furthermore, when sample EA-1 is annealed at $250^{\circ} \mathrm{C}$ for 90 min, the diffusion of $\mathrm{C}$ and $\mathrm{H}$ is enhanced. Similarly based on analysis of samples EA-2 and EA-6, it is inferred that annealing at $250^{\circ} \mathrm{C}$ for 90 min enhances the diffusion of $\mathrm{C}, \mathrm{H}$ and $\mathrm{N}$ into the substrate. By taking the average intensity ratios, the approximate percentage of nitrogen in a sample EA-2 has been estimated to be about 6 at. $\%$. This agrees well with the nitrogen content as estimated by EDAX which is about 7 at.\%. 
Dwivedi et al. ACS Appl. Mater. Interfaces 4, 5309 (2012)

The micro-Raman spectra of nanocrystalline (samples EA-1, EA-2, EA-5 and EA-6) and amorphous (samples EA-9 and EA-10) DLC films are shown in Fig. 4(a). The visible (514.5 nm) Raman spectra of DLC films exhibit two bands, D (disorder) band near $1350 \mathrm{~cm}^{-1}$ and G (graphite) band near $1540 \mathrm{~cm}^{-1}$. Visible Raman spectra are predominantly sensitive to $\mathrm{sp}^{2}$ bonding due to the low energy separation. However, changes in $G$ peak position and $I_{D} / I_{G}$ ratios imply changes in carbon bonding and $\mathrm{sp}^{2}$ carbon clustering. It is well understood that an increase in $G$ peak position from $1520 \mathrm{~cm}^{-1}$ to $1600 \mathrm{~cm}^{-1}$ and an increase in $\mathrm{I}_{\mathrm{D}} / \mathrm{I}_{\mathrm{G}}$ ratio correspond to enhanced $\mathrm{sp}^{2}$ bonding. ${ }^{25}$ From figure $4(\mathrm{a})$, it is evident that the as-deposited samples EA-1 and EA-2 have not only a low D peak intensity (lower disorder) but also had G peak towards lower wavenumber. Among the two samples, sample EA-1 (nc-DLC film) has a lower disorder and G peak shifted towards lower wavenumber side than sample EA-2 (nc-DLC:N film). By contrast, annealing of the films leads to increased disorder with a shifting of the G peak towards higher wavenumber side in annealed samples EA-5 and EA-6. In order to get exact D and G peak position and their $\mathrm{I}_{\mathrm{D}} / \mathrm{I}_{\mathrm{G}}$ ratios, the Raman spectra are fitted by considering two Gaussian components. The variations of $\mathrm{G}$ peak position and $\mathrm{I}_{\mathrm{D}} / \mathrm{I}_{\mathrm{G}}$ ratio for different samples are given in Figs. 4(b), respectively. The position of $G$ peak and $I_{D} / I_{G}$ ratio in sample EA-1 is found to be $1547 \mathrm{~cm}^{-1}$ and 0.391 , respectively, and $1560 \mathrm{~cm}^{-1}$ and 0.665 , respectively, in sample EA-2. For the annealed samples, the position of the $G$ peak and $I_{D} / I_{G}$ ratio in sample EA-5 are found to be $1550 \mathrm{~cm}^{-1}$ and 0.424 , respectively, whereas they are changed to $1570 \mathrm{~cm}^{-1}$ and 1.19 , respectively, in sample EA-6. The nitrogen incorporation and annealing significantly affects the microstructure of these films by increasing the $\mathrm{sp}^{2}$ phase. llie et al. ${ }^{12}$ have also observed increased disorder and hence, enhanced $\mathrm{I}_{\mathrm{D}} / \mathrm{I}_{\mathrm{G}}$ ratio in a-C:H, tetrahedral hydrogenated carbon (ta$\mathrm{C}: \mathrm{H})$ and tetrahedral nitrogenated carbon (ta-C:N) thin films. Ferrari et al. ${ }^{25,26}$ and Rodil et al. ${ }^{27}$ 
have also suggested that the shifting of $G$ peak towards higher wavenumber and increased $\mathrm{I}_{\mathrm{D}} / \mathrm{I}_{\mathrm{G}}$ ratio in amorphous carbon films are accompanied by enhanced $\mathrm{sp}^{2}$ bonding.

Our analysis also infers that thermal annealing had more pronounced behaviour in nitrogen included nc-DLC:N films than pure nc-DLC films. This can be confirmed by analyzing the data of the as-deposited and annealed nc-DLC:N films with respect to the as-deposited and annealed nc-DLC film. The as-deposited nc-DLC:N film (sample EA-2) has a G peak at 1560 $\mathrm{cm}^{-1}$ but it is shifted by $\sim 10 \mathrm{~cm}^{-1}$ towards higher wavenumber side in $250^{\circ} \mathrm{C}$ annealed nc-DLC:N film (sample EA-6) and found to be at $1570 \mathrm{~cm}^{-1}$. Similarly, the $\mathrm{I}_{\mathrm{D}} / \mathrm{I}_{\mathrm{G}}$ ratio in sample EA-2 is found to be 0.665 , which is larger than the value of 0.12 in sample EA-6. By contrast, the asdeposited nc-DLC film (sample EA-1) had a G peak at $1547 \mathrm{~cm}^{-1}$ which is shifted by only $3 \mathrm{~cm}^{-1}$ towards higher wavenumber side in $250^{\circ} \mathrm{C}$ annealed nc-DLC film (sample EA-5) and found to be at $1550 \mathrm{~cm}^{-1}$. The $\mathrm{I}_{\mathrm{D}} / \mathrm{I}_{\mathrm{G}}$ ratio in sample EA-1 is found to be 0.39 , which is increased to 0.42 in sample EA-5.

Temperature induced structural transformation are more pronounced in nc-DLC:N film and give rise to the creation of more $\mathrm{sp}^{2}$ bonding in annealed nc-DLC:N film (sample EA-6). The $\mathrm{G}$ peak position and $\mathrm{I}_{\mathrm{D}} / \mathrm{I}_{\mathrm{G}}$ ratio in comparatively higher self-bias deposited a-DLC film (sample EA-9) are found at $1551 \mathrm{~cm}^{-1}$ and 0.453 , respectively. These are increased to $1563 \mathrm{~cm}^{-1}$ and 0.7 , respectively, in a-DLC:N film (sample EA-10) due to nitrogen driven enhanced $\mathrm{sp}^{2}$ bonding. The difference in the $\mathrm{G}$ peak position and $\mathrm{I}_{\mathrm{D}} / \mathrm{I}_{\mathrm{G}}$ ratio between $-100 \mathrm{~V}$ and $-180 \mathrm{~V}$ self-bias grown ncDLC and a-DLC; nc-DLC:N and a-DLC:N films are found to be small which suggests that at a higher self-bias of $-180 \mathrm{~V}$ an increase in $\mathrm{sp}^{2}$ bonding takes place. FTIR is found to be an important tool for investigating the bonding environment of DLC and modified DLC thin films. Figures 5(a)-5(b) shows the FTIR spectra of sample EA-1 and EA-2 in the range $1200-2200$ $\mathrm{cm}^{-1}$ and $2700-3500 \mathrm{~cm}^{-1}$, respectively. Sample EA-1, which is a pure nc-DLC film, shows 
various vibrating modes such as the $\mathrm{C}-\mathrm{H}_{\mathrm{n}}$ stretching mode in the range $2700-3150 \mathrm{~cm}^{-1}, \mathrm{C}-\mathrm{H}_{\mathrm{n}}$ bending mode (or olefinic mode) in the range $1300-1550 \mathrm{~cm}^{-1}$. The FTIR spectra also shows an important peak corresponding to $\mathrm{C}=\mathrm{C}$ vibrations in the band $1560-1660 \mathrm{~cm}^{-1}$ and $\mathrm{OH}$ bonding above $3200 \mathrm{~cm}^{-1}$. When nitrogen is introduced in nc-DLC film, two changes are realized in the nc-DLC:N film (sample EA-2). First, the intensity of the peak in the range $1560-1660 \mathrm{~cm}^{-1}$ is significant increased, which is attributed to nitrogen introduction promoting the formation of $\mathrm{C}=\mathrm{N}$ bonding (enhanced $\mathrm{sp}^{2}$ bonding). Second, the intensity of the $\mathrm{C}-\mathrm{H}_{\mathrm{n}}$ stretching vibrations is reduced, which is due to the fact that nitrogen inclusion may replace some of the $\mathrm{C}$ atoms in $\mathrm{C}$ $\mathrm{H}_{n}$ stretching vibrations and generate $\mathrm{N}-\mathrm{H}$ based bonding above $3150 \mathrm{~cm}^{-1}$. The optical and nano-mechanical properties of these EA samples are examined and discussed in brief here. Sample EA-1 with an optical band gap of $1.7 \mathrm{eV}$ shows highest hardness as $35.8 \mathrm{GPa}$. However, introduction of nitrogen, annealing and increase in self bias leads to reduction of hardness owing enhanced $\mathrm{sp}^{2}$ bonding. The optical property also supports the increase in $\mathrm{sp}^{2}$ bonding due to introduction of nitrogen because optical band gap in sample EA-2 reduces to $1.1 \mathrm{eV}$. Thus, optical and nano-mechanical properties infer that sample EA-1 possesses more $\mathrm{sp}^{3}$ bonding due to its higher hardness and large band gap.

The field emission current (I) versus field (E) curves of sample EA-1 recorded over various successive cycles are shown in Fig. 6(a). Moving from run 1 to run 4, the threshold field is found to reduce from $\sim 2.1 \mathrm{~V} / \mu \mathrm{m}$ to $1.25 \mathrm{~V} / \mu \mathrm{m}$. Not only this, the emission current $\left(\mathrm{I}_{\mathrm{E}}\right)$ is also found to be highest in run 4 . The recorded I-E characteristics of sample EA-1 in various runs are fitted with a Fowler-Nordheim (F-N) model in Fig. 6(b), where a plot of $\ln \left(\mathrm{J} / \mathrm{E}^{2}\right)$ versus $1 / \mathrm{E}$ is shown. The F-N theory is related to the emission of electrons from the front surface via tunneling ${ }^{5,28}$ through an approximately triangular barrier. The Fowler-Nordheim equation takes the form 


$$
J=\frac{a(\beta E)^{2}}{\phi} \exp \left(\frac{-b \phi^{3 / 2}}{\beta E}\right),
$$

where $\mathrm{J}$ is the current density, $\Phi$ is the potential barrier height (taken as the work function), $\mathrm{E}$ is the applied (or macroscopic) electric field, $\beta$ is the field enhancement factor and $a$ and $b$ are constants and have the values of $1.56 \times 10^{-6} \mathrm{~A} \mathrm{eVV}^{-2}$ and $6.83 \times 10^{7} \mathrm{VeV}^{-3 / 2} \mathrm{~cm}^{-1}$, respectively. It can be seen that these emission curves are well fitted in their F-N plots, confirming that the electrons are emitted by cold cathode emission process. With the help of such F-N plots the field enhancement factor $(\beta)$ can be estimated for a given value of $\Phi$, taken as $5 \mathrm{eV}$. The parameter $\beta$ is associated with the generation of the local field rather than the applied field and is normally expressed in terms of ratio of local $\left(E_{\text {local }}\right)$ to applied (E) field. If $\beta$ is large then lower applied fields can generate same the high local fields necessary for good field emission. The value of $\beta$ is found to vary from 7620 to 8962 for sample EA-1 from run 1 to run 4 which explains the reduction in the threshold applied field.

Depending upon film structure, two types of field emission mechanisms are possible in amorphous and nanostructured carbon films. Generally low bias grown polymer-like amorphous carbon (PAC) films with fewer defects and low conductivity show back contact controlled field emission due to the formation of leaky barrier at the film/back contact interface. In contrast, comparatively higher self-bias grown DLC and nc-DLC films having high defect density and higher the conductivity exhibit front surface based emission. ${ }^{5}$ Various models have been suggested with regard to the explanation of field emission from DLC thin films, but a complete interpretation remains unresolved. The situation becomes difficult when $\mathrm{E}_{\mathrm{T}}$ reaches below 5 $\mathrm{V} / \mu \mathrm{m}$; Ikeda and $\mathrm{Teii}^{23}$ have observed a low value of $\mathrm{E}_{\mathrm{T}} \sim 3 \mathrm{~V} / \mu \mathrm{m}$ in nanodiamond films and suggested a possible reason based on defect-induced conduction that becomes stronger under nitrogen inclusion. Previously Carey et al..$^{29}$ had suggested that defect and localized states near 
the Fermi level in the form of $\mathrm{sp}^{2}$ clusters in the $\mathrm{sp}^{3}$ matrix help to obtain efficient field emission with $\mathrm{E}_{\mathrm{T}}$ below $10 \mathrm{~V} / \mu \mathrm{m}$. Normally, $\mathrm{sp}^{2}$ clusters in DLC films are distributed in the $\mathrm{sp}^{3}$ matrix; in diamond and polycrystalline diamond films the conducting $\mathrm{sp}^{2}$ bonded grain boundaries surround the $\mathrm{sp}^{3}$ bonded grains. The same explanation used for diamond and polycrystalline diamond is also applicable for the present nc-DLC film (or nanodiamond film sample EA-1), where $\mathrm{sp}^{3}$ bonded nanodiamond grains are bordered with $\mathrm{sp}^{2}$ bonded grain boundries. However, in contrast to diamond and polycrystalline diamond films, nc-DLC or nanodiamond film possesses more grain boundaries. Since diamond grains with $\mathrm{sp}^{3}$ bonding exhibit low and even negative electron affinity (NEA), the electrons see a negligible potential barrier for emission and are emitted at lower $\mathrm{E}_{\mathrm{T}}$. Under the action of an external field, a large local field will be generated around the $\mathrm{sp}^{2}$ bonded grain boundaries due to termination of the field lines. As a result both $\mathrm{sp}^{2}$ bonding and $\mathrm{sp}^{3}$ bonding play an important role for field emission from nc-DLC films.

Optimum values of $\mathrm{sp}^{3}$ and $\mathrm{sp}^{2}$ bonding are needed for optimum field emission from ncDLC films. It is important to mention that in contrast to unhydrogenated counterpart, hydrogenated DLC and nc-DLC film (with certain amount of hydrogen) exhibit high $\mathrm{sp}^{3}$ bonding as well as low electron affinity. Since a low value of $\mathrm{E}_{\mathrm{T}}$ is realized in sample EA-1, a possible model pertaining to explain the field emission behaviour is schematically depicted in Fig. 7. In present model, we refer $\mathrm{sp}^{2}$ bonded conducting grain boundaries as a 'conducting pathway' and the surrounding $\mathrm{sp}^{3}$ bonded nanodiamond grains are treated as dielectric (insulator/semiconductor) regions. These $\mathrm{sp}^{2}$ bonded conducting pathways may have a high aspect ratio forming an effective percolating network pathway in the film. Recently, Varshney et $a l .{ }^{30}$ have fabricated a diamond and CNT composite structure and observed low $\mathrm{E}_{\mathrm{T}}$ and high $\mathrm{I}_{\mathrm{E}}$ characteristics during field emission measurement. They have suggested that CNTs have a high aspect ratio and during field emission heat is produced in CNTs. The $\mathrm{sp}^{3}$ diamond grains act as a 
heat sink and help to maintain the efficient field emission property of overall structure. Similarly in sample EA-1, under the action of an external field the $\mathrm{sp}^{2}$ bonded conducting pathways may be heated due to predominant emission of electrons through this region. Among the four runs, run 4 exhibit lowest $\mathrm{E}_{\mathrm{T}}$ and highest $\mathrm{I}_{\mathrm{E}}$; attributed to current induced transformation of $\mathrm{sp}^{3}$ bonding into $\mathrm{sp}^{2}$ bonding. ${ }^{31}$

In order to explore the influence of nitrogen incorporation and annealing on the field emission characteristics of nc-DLC and modified nc-DLC films, the field emission I-E curves of different nc-DLC based devices are recorded (samples EA-1 to EA-6), as shown in Fig. 8(a). Here, it is found that among all samples, the sample EA-1 shows lowest $\mathrm{E}_{\mathrm{T}}$ at $1.25 \mathrm{~V} / \mu \mathrm{m}$. However, when sample EA-1 is annealed at $150^{\circ} \mathrm{C}$ for $90 \mathrm{~min}$, the value of $\mathrm{E}_{\mathrm{T}}$ in sample EA-3 is slightly increased to $1.76 \mathrm{~V} / \mu \mathrm{m}$. Nevertheless, when the temperature for annealing of sample EA-1 is increased to $250^{\circ} \mathrm{C}$ (for $90 \mathrm{~min}$ ), the value of $\mathrm{E}_{\mathrm{T}}$ in sample EA-5 is drastically enhanced to $9.8 \mathrm{~V} / \mu \mathrm{m}$, which is found to be the highest $\mathrm{E}_{\mathrm{T}}$ among all the nc-DLC samples. This infers that annealing of these nc-DLC films modifies the film structure and affects the electron emission. Based on a change of $0.51 \mathrm{~V} / \mu \mathrm{m}$ in $\mathrm{E}_{\mathrm{T}}$ between samples EA-1 and EA-3, it is realized that annealing at low temperature $\left(150^{\circ} \mathrm{C}\right)$ has a less pronounced effect on field emission properties of nc-DLC films. When annealing temperature is raised to $250^{\circ} \mathrm{C}$, the structure of the film gets changed considerably (e.g. the generation of more $\mathrm{sp}^{2}$ clustering as confirmed by Raman analysis and the enhanced diffusion of atoms as measured by ToF-SIMS) that causes the largest shift of $\mathrm{E}_{\mathrm{T}}$ of $8.6 \mathrm{~V} / \mu \mathrm{m}$ between samples EA-1 and EA-5. When nitrogen is introduced, the value of $\mathrm{E}_{\mathrm{T}}$ in sample EA-2 is significantly increased to $8.3 \mathrm{~V} / \mu \mathrm{m}$. This is due to the fact that introduction of nitrogen significantly modifies the structure of resulting sample EA-2 and increases the $\mathrm{sp}^{2}$ bonding, as confirmed by Raman and FTIR analyses. Furthermore, when sample EA-2 is 
annealed at $150^{\circ} \mathrm{C}$ and $250^{\circ} \mathrm{C}$ for $90 \mathrm{~min}$, the value of $\mathrm{E}_{\mathrm{T}}$ in samples $\mathrm{EA}-4$ and $\mathrm{EA}-6$ is increased to $8.4 \mathrm{~V} / \mu \mathrm{m}$ and $9.2 \mathrm{~V} / \mu \mathrm{m}$, respectively.

Not only is the value of $\mathrm{E}_{\mathrm{T}}$ but also the magnitude of maximum $\mathrm{I}_{\mathrm{E}}$ varied significantly with the changing annealing temperature and the introduction of nitrogen. We believe that the annealing and nitrogen inclusion disturbs the optimum ratio of $\mathrm{sp}^{3}$ bonded dielectric regions (nano-grains) and $\mathrm{sp}^{2}$ bonded conducting pathways (grains boundaries) and hence, enhanced the $\mathrm{E}_{\mathrm{T}}$ and lower $\mathrm{I}_{\mathrm{E}}$. The increased value of $\mathrm{E}_{\mathrm{T}}$ in samples EA-5 and EA-6 are also correlated with interdiffusion of $\mathrm{C}, \mathrm{H}$ and $\mathrm{N}$ into $\mathrm{Si}$ as studied by ToF-SIMS. As annealing of sample EA-1 at $250^{\circ} \mathrm{C}$ leads to enhanced diffusion of $\mathrm{C}$ and $\mathrm{H}$ elements into $\mathrm{Si}$, which results in large mismatches at the interface and hence, contribute enhancing the value of $\mathrm{E}_{\mathrm{T}}$ of sample EA-5. Similarly, annealing of sample EA-2 at $250^{\circ} \mathrm{C}$ enhanced the diffusion of $\mathrm{C}, \mathrm{H}$ and $\mathrm{N}$ species into $\mathrm{Si}$ that further enhances the interfacial mismatch and therefore, helps increasing the $\mathrm{E}_{\mathrm{T}}$ of resultant sample EA-6. The interdiffusion of these elements may also disturb the electrical characteristics of the back contact making the back contact more resistive explaining the large values of $E_{\mathrm{T}}$ obtained in annealed samples than that of as-deposited samples.

The influence of morphology and self-bias on field emission property of carbon films are also explored. The I-E characteristics of a-DLC (sample EA-9) and a-DLC:N films (sample EA10) are recorded is shown in Fig. 8(a). The value of $E_{T}$ and the maximum value of $I_{E}$ in a-DLC film (sample EA-9) are found to be $7.6 \mathrm{~V} / \mu \mathrm{m}$ and $2.7 \times 10^{-5} \mathrm{~A}$, respectively. On the other hand, aDLC:N film exhibits a comparatively higher vaue of $\mathrm{E}_{\mathrm{T}}$ and lower current. In sample EA-10 initial emission begins at $9.77 \mathrm{~V} / \mu \mathrm{m}$ which is higher than the value of $\mathrm{E}_{\mathrm{T}}$ of sample EA-9 due to nitrogen induced structural changes as confirmed by micro-Raman analysis. When compared the values of $\mathrm{E}_{\mathrm{T}}$ of sample EA-9 with EA-1, the value of $\mathrm{E}_{\mathrm{T}}$ is found to be significantly larger in EA9, which is due to fact that EA-1 possess nanostructure (some geometrical structure that helps 
enhancing local field) whereas EA-9 shows an amorphous structure (no geometrical enhancement ). Similarly, the value of $\mathrm{E}_{\mathrm{T}}$ of EA-10 is found to be larger than that of EA-2 due to the amorphous structure and higher self-bias growth of former sample.

Examining the current research on carbon based materials for field emission applications; Talapatra et al. ${ }^{2}$ have demonstrated the lowest $\mathrm{E}_{\mathrm{T}}$ as $3.22 \mathrm{~V} / \mu \mathrm{m}$ in his MWCNT sample. On the other hand, Varshney et al. $^{7}$ have obtained a low value of $\mathrm{E}_{\mathrm{T}}$ as $2.4 \mathrm{~V} / \mu \mathrm{m}$ in a complex graphene-diamond hybrid film. They have also reduced $\mathrm{E}_{\mathrm{T}}$ to $1.1 \mathrm{~V} / \mu \mathrm{m}$ (at a current $\sim 10^{-8} \mathrm{~A}$ ) in complex and expensive nanotube/diamond composite ${ }^{30}$ but the value of $\mathrm{E}_{\mathrm{T}}$ in this sample is found to be $4 \mathrm{~V} / \mu \mathrm{m}$ at current $\sim 10^{-5} \mathrm{~A}$. They have also observed $\mathrm{E}_{\mathrm{T}}$ of $5-6 \mathrm{~V} / \mu \mathrm{m}$ in complex rod-shaped DLC nanostructures. ${ }^{32}$ Shimada et al. ${ }^{33}$ have also observed low $\mathrm{E}_{\mathrm{T}}$ as $\sim 3 \mathrm{~V} / \mu \mathrm{m}$ in their complex and unconventional carbon nanowalls structure. Moreover Ikeda and Teii ${ }^{23}$ have realized $\mathrm{E}_{\mathrm{T}}$ as $3 \mathrm{~V} / \mu \mathrm{m}$ in nanocrystalline diamond. In our case of nc-DLC film (sample EA-1) the value of $E_{T}$ of $1.25 \mathrm{~V} / \mu \mathrm{m}$ must be seem to be very encouraging. All the I-E characteristics of the samples are fitted to F-N plots. Since, F-N plots of samples EA-2, EA-4, EA-5, EA-6, EA-9 and EA-10 overlap each other, hence we have sketched F-N plots of samples EA-1 and EA-3 seperately, which as shown in Fig. 8(b) and F-N plots of samples EA-2, EA-4, EA-5, EA-6, EA9 and EA-10 are given in Fig. 8(c). Here all emission curves properly fitted for F-N plots confirming electrons are emitted from the front surface. It is to be noted that sample EA-10 possesses two slopes; one in low field and other in comparatively higher field; as represented by S1 and S2, respectively which usually signifies the presence of current saturation at the higher field values. ${ }^{8}$ 


\section{CONCLUSIONS}

In conclusion, we have demonstrated low threshold field emission in a simple and inexpensive nanocrystalline DLC thin film. We have explained the data in terms of model based

upon conducting pathways of $\mathrm{sp}^{2}$ bonded carbon surrounded by dielectric regions of $\mathrm{sp}^{3}$ bonded carbon. We believe that this lowest threshold field could be obtained from an optimum amount of $\mathrm{sp}^{3}$ and $\mathrm{sp}^{2}$ bonding. The addition of nitrogen and thermal annealing both results in increased value of threshold field, which was attributed to the introduction of increased disorder and enhanced interdiffusion of $\mathrm{C}$ and $\mathrm{H}$ species into the substrate $\mathrm{Si}$. The effects of self-bias and surface morphology have also been examined. Compared with -100 V deposited nanocrystalline counterpart, the threshold field is found to be higher in higher self-bias deposited amorphous DLC and nitrogenated amorphous DLC thin films. Owing to excellent field emission characteristic with low threshold field, nc-DLC films have great potential for large area electronic devices.

\section{ACKNOWLEDGEMENTS}

The authors are grateful to the Director, National Physical Laboratory, New Delhi (India) for his kind support. The authors wish to thank Mr. Ishpal, Mr. C. M. S. Rauthan, Dr. O. S. Panwar and Ms. Geetanjali Sehgal for their help. ND acknowledges CSIR, Govt. of India for providing financial support through SRF fellowship. CSIR, Govt. of India is also acknowledged for rendering a Network Project NWP-0027. 


\section{REFERENCES}

(1) Mochalin, V. M.; Shenderova, O.; Ho, D.; Gogotsi, Y. Nature Nanotech. 2012, 7, 11.

(2) Talapatra, S.; Kar, S.; Pal, S. K.; Vajtai, R.; Cl, L.; Victor, P.; Shaijumon, M. M.; Kaur, S.; Nalamasu, O.; Ajayan, P. M. Nature Nanotech. 2006, 1, 112.

(3) Bhattacharyya, S.; Henley, S. J.; Mendoza, E.; Rojas, L. G.; Allam, J.; Silva, S. R. P. Nature Mater. 2006, 5, 19.

(4) Wu, Y.; Lin, Y. M.; Bol, A. A.; Jenkins, K. A.; Xia, F.; Farmer, D. B.; Zhu, Y.; Avouris, P. Nature 2011, 472, 74.

(5) Carey, J. D. Philos. Transc. R. Soc. Lond. A 2003, 361, 2891.

(6) Biswas, C.; Lee, Y. H. Adv. Funct. Mater. 2011, 21, 3806.

(7) Varshney, D.; Rao, C. V.; Guinel, M. J. F.; Ishikawa, Y.; Weiner, B. R.; Morell, G. J. Appl. Phys. 2011, 110, 044324.

(8) Connolly, T.; Smith, R. C.; Hernandez, Y.; Gun'ko, Y.; Coleman, J. N.; Carey, J. D. Small 2009, 5, 826.

(9) Robertson, J. Semicond. Sci. Technol. 2003, 18, 12.

(10) Schwan, J.; Batori, V.; Ulrich, S.; Ehrhardt, H.; Silva, S. R. P. J. Appl. Phys. 1998, 84, 2071.

(11) Silva, S. R. P.; Robertson, J.; Amaratunga, G. A. J.; Rafferty, B.; Brown, L. M.; Schwan, J.; Franceschini, D. F.; Marriotto, G. J. Appl. Phys. 1997, 81, 2626.

(12) llie, A. ; Ferrari, A. C.; Yagi, T. ; Rodil, S. E.; Robertson, J.; Barborini, E.; Milani, P. J. Appl. Phys. 2001, 90, 2024.

(13) Konofaos, N.; Thomas, C. B. Appl. Phys. Lett. 1992, 61, 2805.

(14) Godet, C.; Conway, N. M. J.; Bouree, J. E.; Bouamra, K.; Grosman, A.; Ortega, C. J. Appl. Phys. 2002, 91, 4154. 
Dwivedi et al. ACS Appl. Mater. Interfaces 4, 5309 (2012)

(15) Dwivedi, N.; Kumar, S.; Malik, H. K. J. Appl. Phys. 2012, 111, 014908.

(16) Dwivedi, N.; Kumar, S.; Malik, H. K. ACS Appl. Mater. Interfaces 2011, 3, 4268.

(17) Dwivedi, N.; Kumar, S.; Malik, H. K. Solar Energy 2012, 86, 220.

(18) Dwivedi, N.; Kumar, S.; Tripathi, R. K.; Malik, H. K.; Panwar, O. S. Appl. Phys. A 2011, $105,417$.

(19) Dwivedi, N.; Kumar, S.; Rauthan, C. M. S.; Panwar, O. S. Plasma Process. Polym. 2011, $8,100$.

(20) Carey, J. D.; Forrest, R. D.; Khan, R. U. A.; Silva, S. R. P. Appl. Phys. Lett. 2000, 77, 2006

(21) Carey, J. D.; Smith, R. C.; Silva, S. R. P. J. Mater. Sci.:Mater. Electron. 2006, 17405.

(22) Forest, R. D.; Burden, A. P.; Silva, S. R. P.; Cheah, L. K.; Shi, X. Appl. Phys. Lett. 1998, 73,3784 .

(23) Ikeda, T.; Teii, K. Appl. Phys. Lett. 2009, 94, 143102.

(24) Standard data, JCPDS Card numbers 791473, 791471, 791470, 731664, 752078 and 791715.

(25) Ferrari, A. C. ; Robertson, J. Philos. Trans. R. Soc. Lond. A 2004, 362, 2477.

(26) Ferrari, A. C.; Rodil, S. E.; Robertson, J. Phys. Rev. B 2003, 67, 155306.

(27) Rodil, S. E.; Ferrari, A. C.; Robertson, J.; Milne, W. I. J. Appl. Phys. 2001, 89, 5425.

(28) Fowler, R. H.; Nordheim, L. Proc. R. Soc. Lond. A 1928, 119, 173.

(29) Carey, J. D.; Forrest, R. D.; Silva, S. R. P. Appl. Phy. Lett. 2001, 78, 2339.

(30) Varshney, D.; Weiner, B. R.; Morell, G. Carbon 2010, 48, 3353.

(31) Carey, J. D.; Silva, S. R. P. Appl. Phys. Lett. 2001, 78, 347.

(32) Varshney, D.; Makarov, V. I.; Saxena, P.; Berrios, A. G.; Scott, J. F.; Weiner, B. R.; Morell, G. Nanotechnology 2010, 21, 285301. 
Dwivedi et al. ACS Appl. Mater. Interfaces 4, 5309 (2012)

(33) Shimada, S.; Teii, K.; Nakashima, M. Diamond Relat. Mater. 2010, 19, 956.

\section{FIGURE CAPTIONS}

Figure 1: Scanning electron microscope images of (a) sample EA-1, (b) sample EA-2, (c) sample EA-5 and (d) sample EA-9.

Figure 2: X-ray diffraction spectra of (a) sample EA-1 and (b) sample EA-2.

Figure 3: ToF-SIMS profiles of (a) sample EA-1, (b) sample EA-5, (c) sample EA-2 and (d) sample EA-6.

Figure 4: (a) Micro-Raman spectra of EA samples and (b) variation of $G$ peak and $I_{D} / I_{G}$ ratio for different samples.

Figure 5: FTIR spectra of samples EA-1 and EA-2 in the ranges (a) $1200-2200 \mathrm{~cm}^{-1}$ and (b) $2700-3500 \mathrm{~cm}^{-1}$.

Figure 6: (a) Field emission I-E curves of sample EA-1 taken at different runs and (b) FowlerNordheim plots of sample EA-1 for different runs.

Figure 7: Proposed model where diamond grains are considered as dielectric regions and graphite grain boundaries are considered as conducting pathways.

Figure 8: (a) Field emission I-E curves of different EA samples and (b) F-N plots of EA samples and (c) F-N plots of samples EA-2, EA-4, EA-5, EA-6, EA-9 and EA-10. 

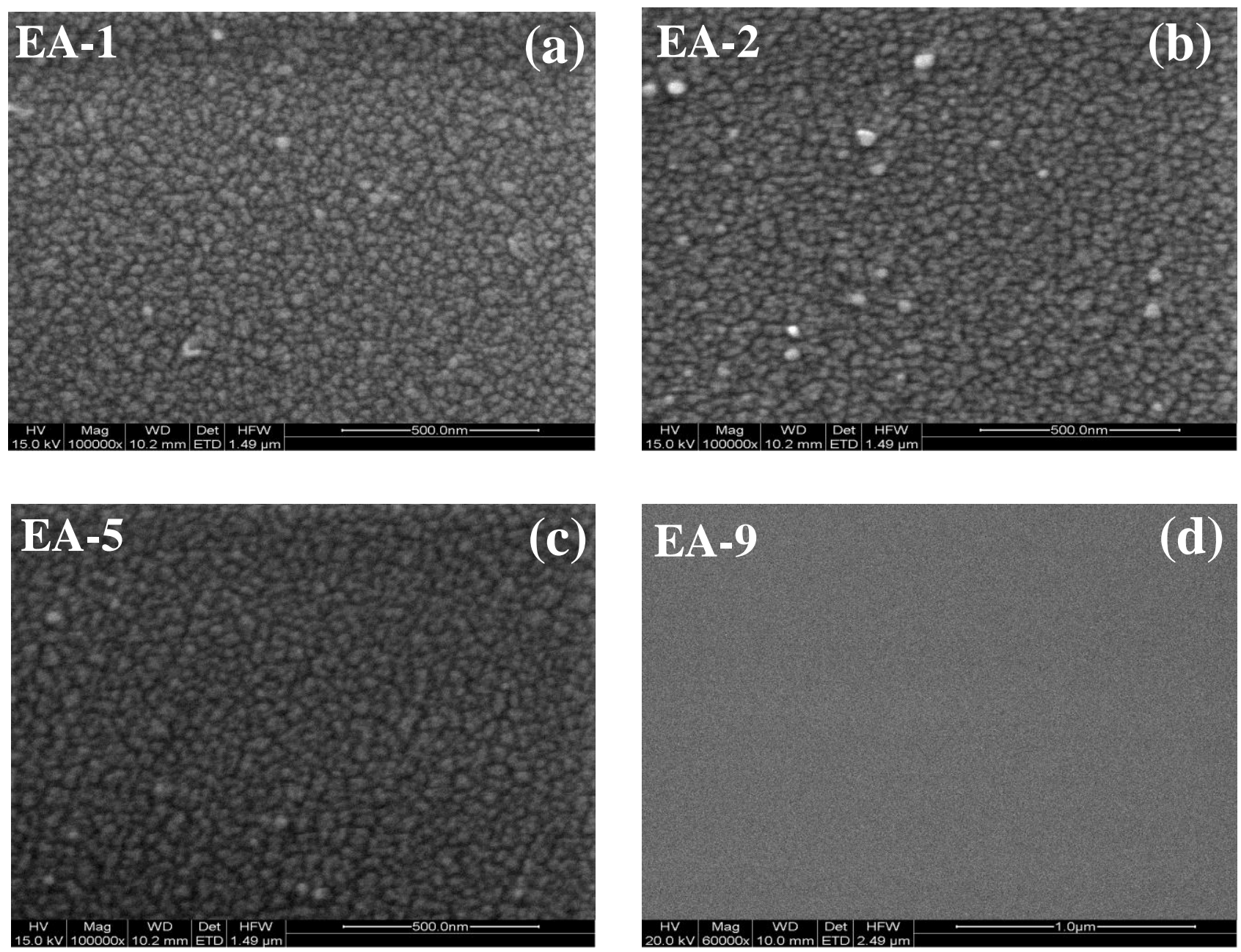

Figure 1 

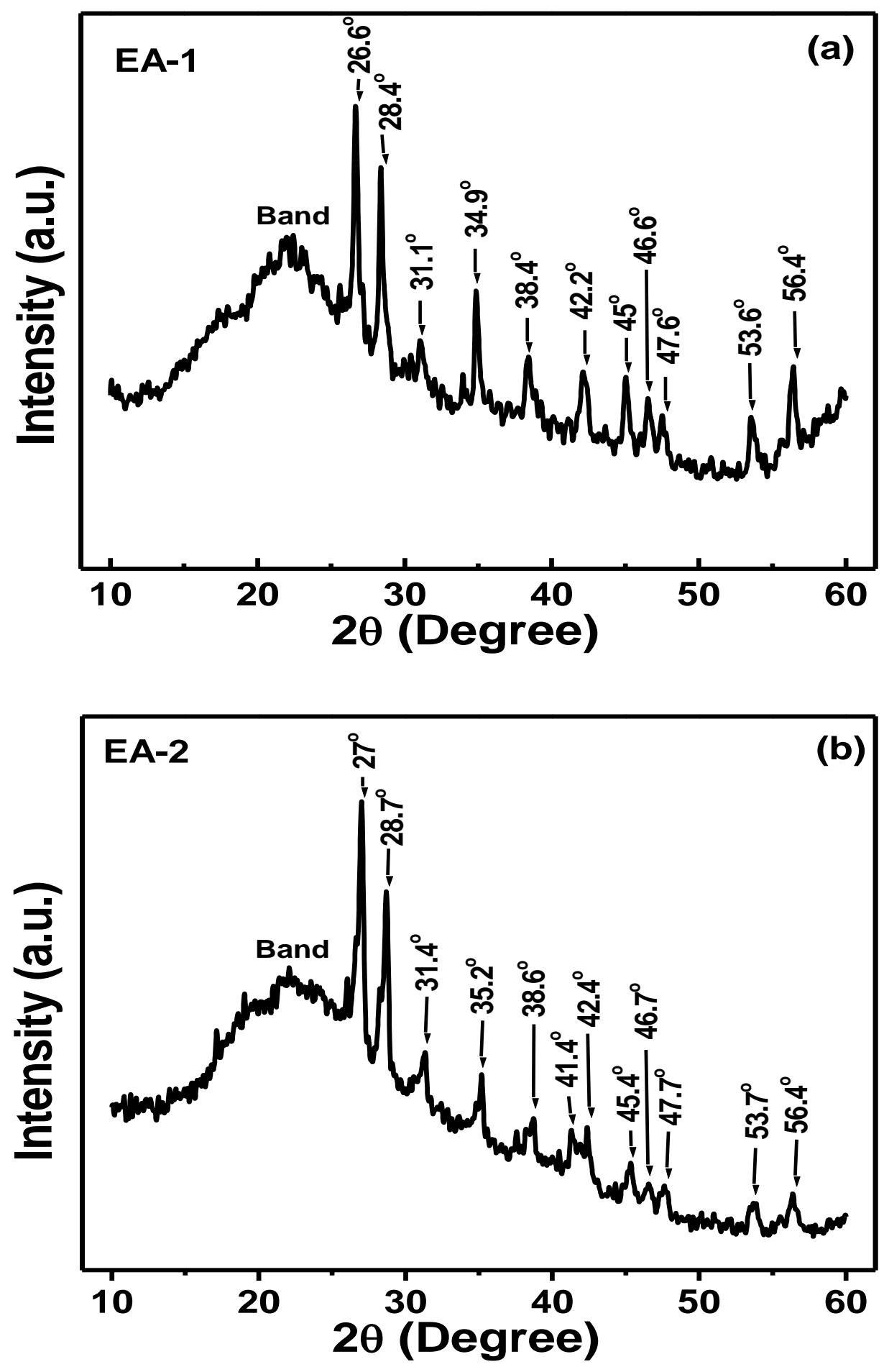

Figure 2 
Dwivedi et al. ACS Appl. Mater. Interfaces 4, 5309 (2012)
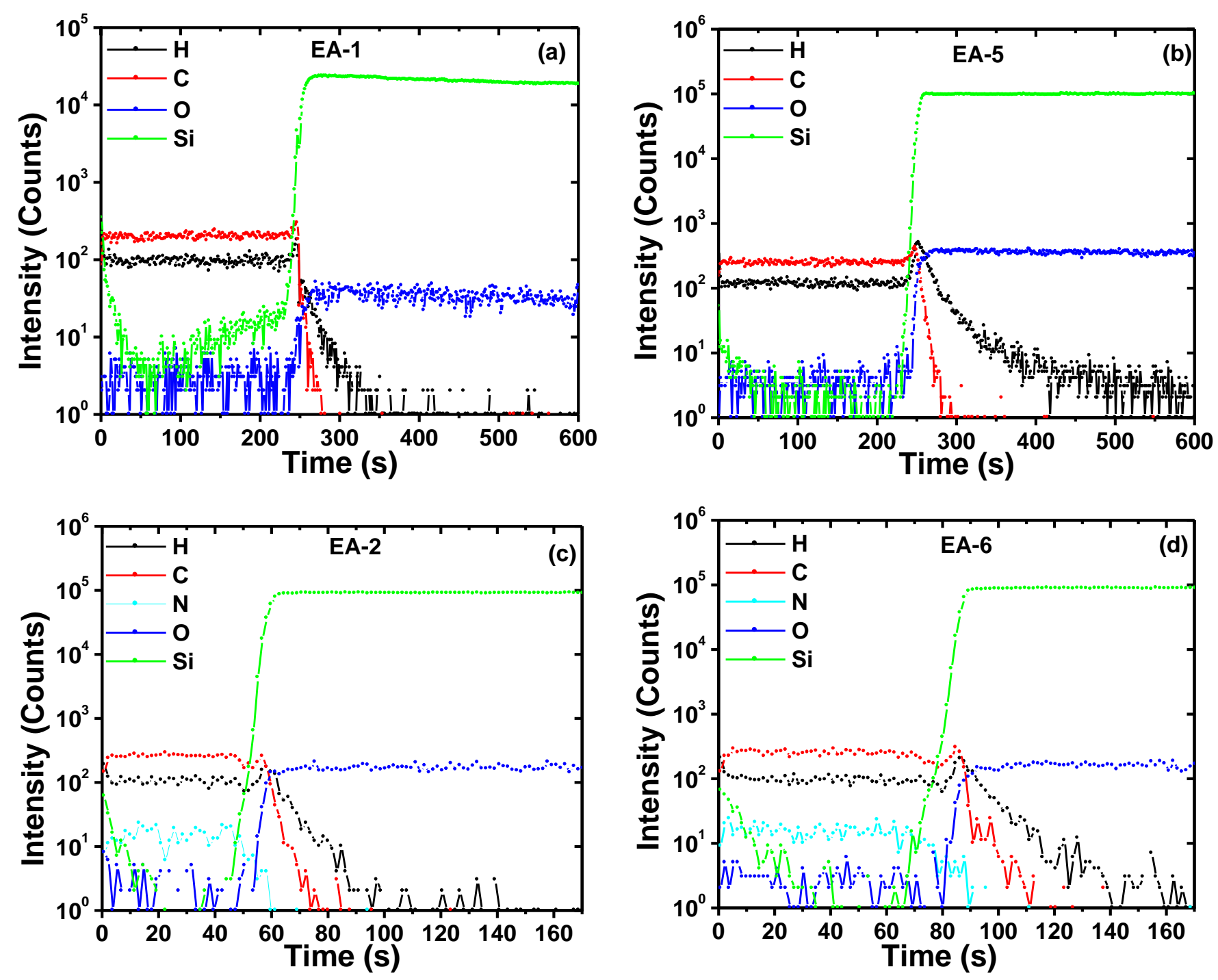

Figure 3 

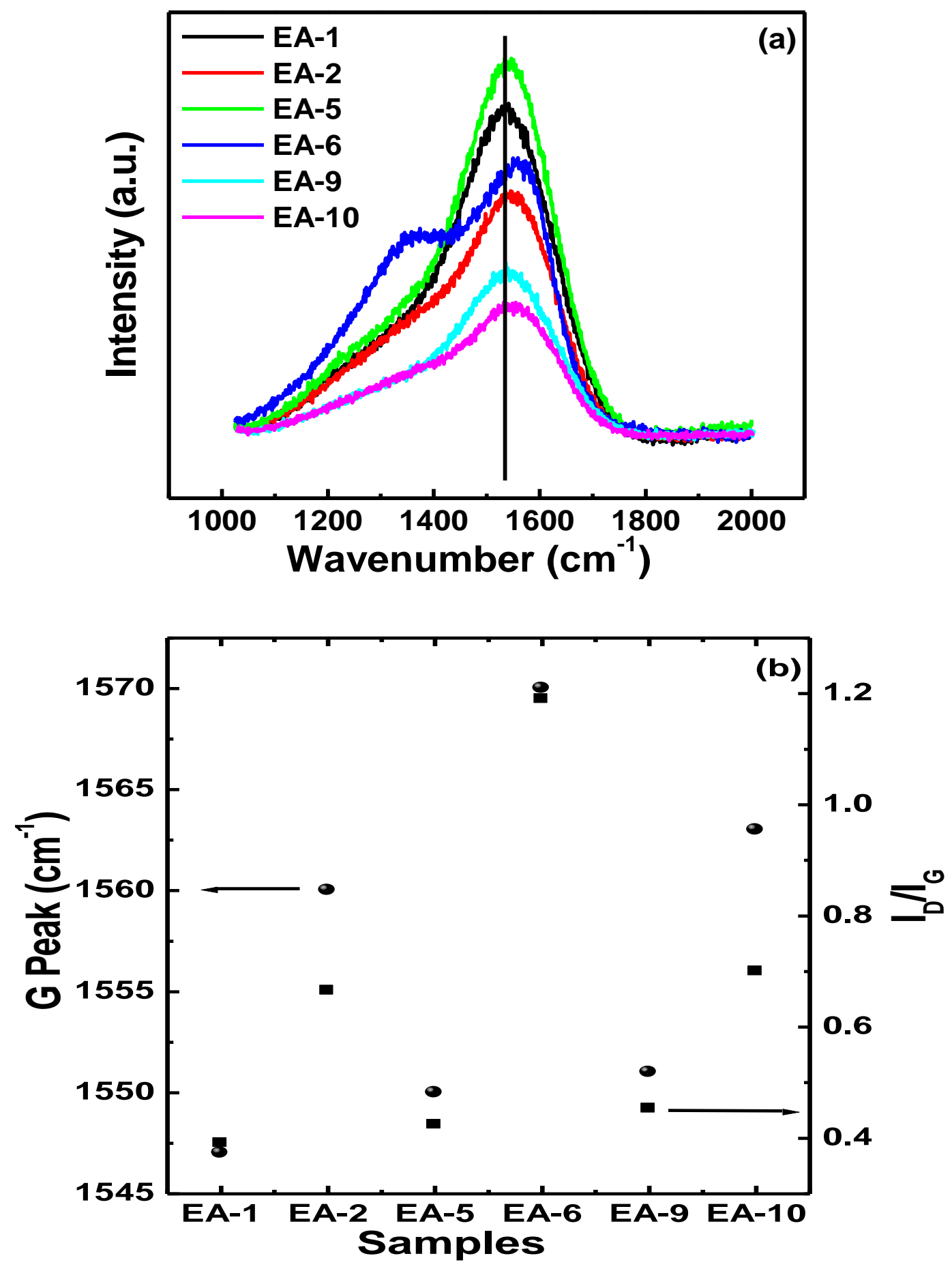

Figure 4 

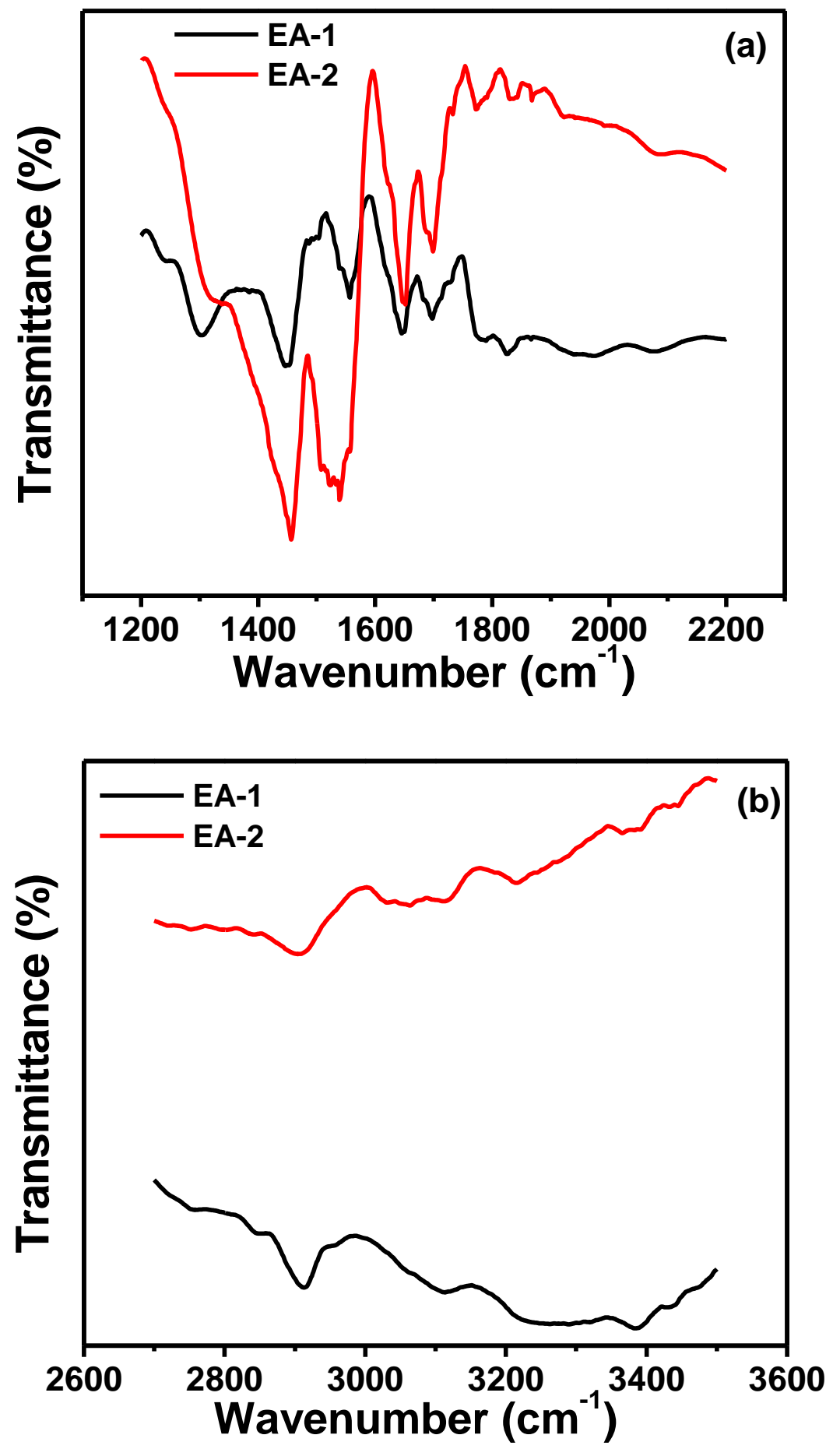

Figure 5 

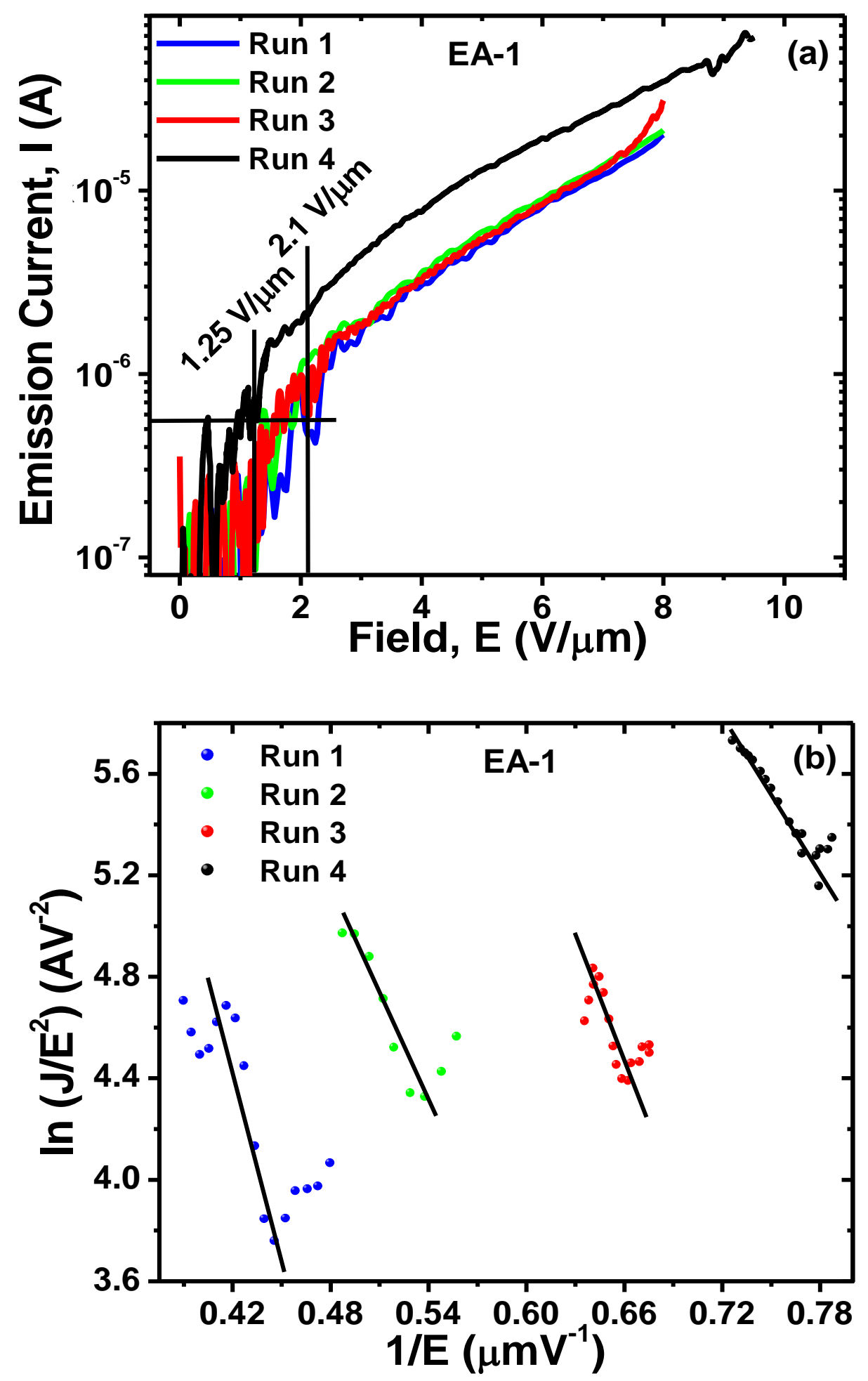

Figure 6 
Dwivedi et al. ACS Appl. Mater. Interfaces 4, 5309 (2012)

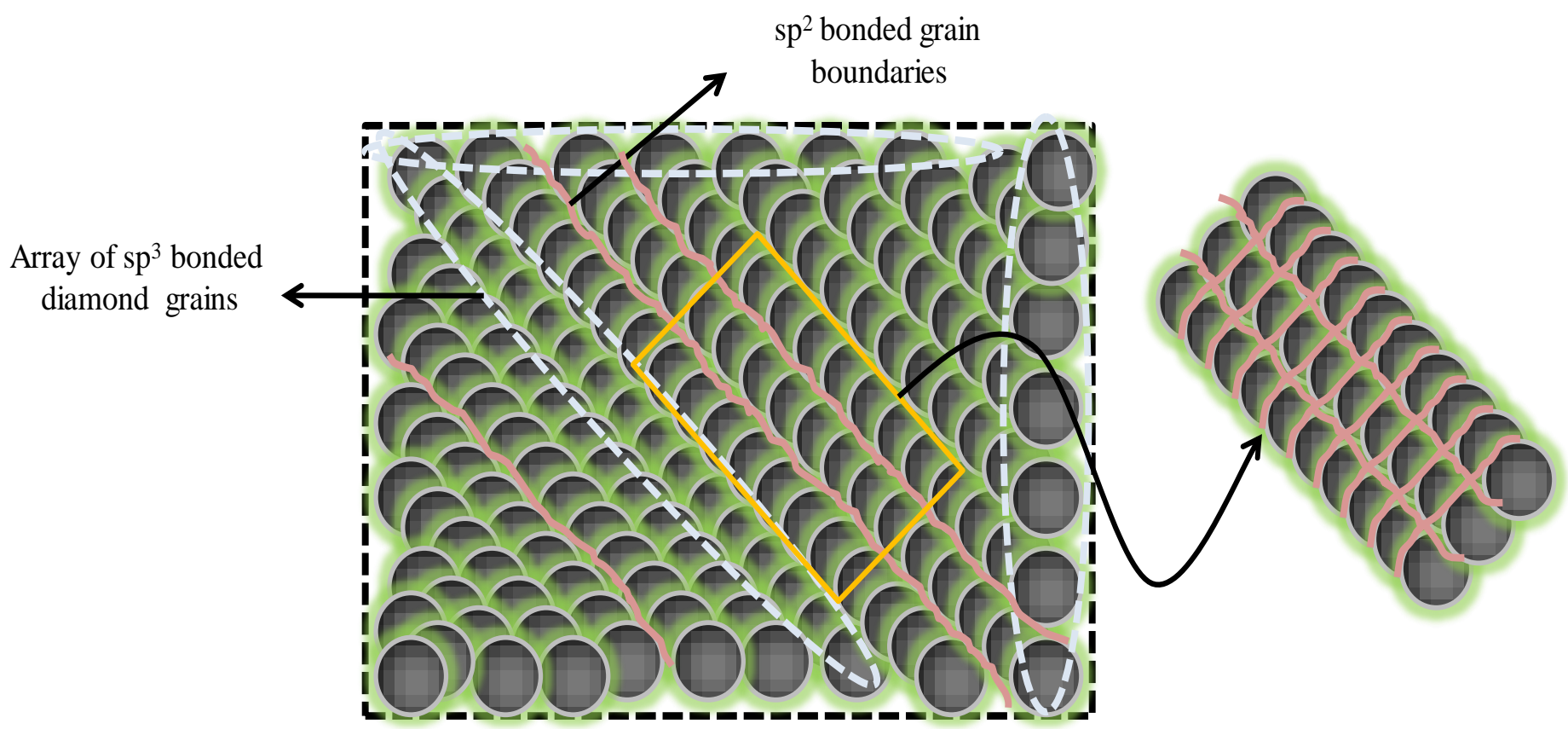

Figure 7 

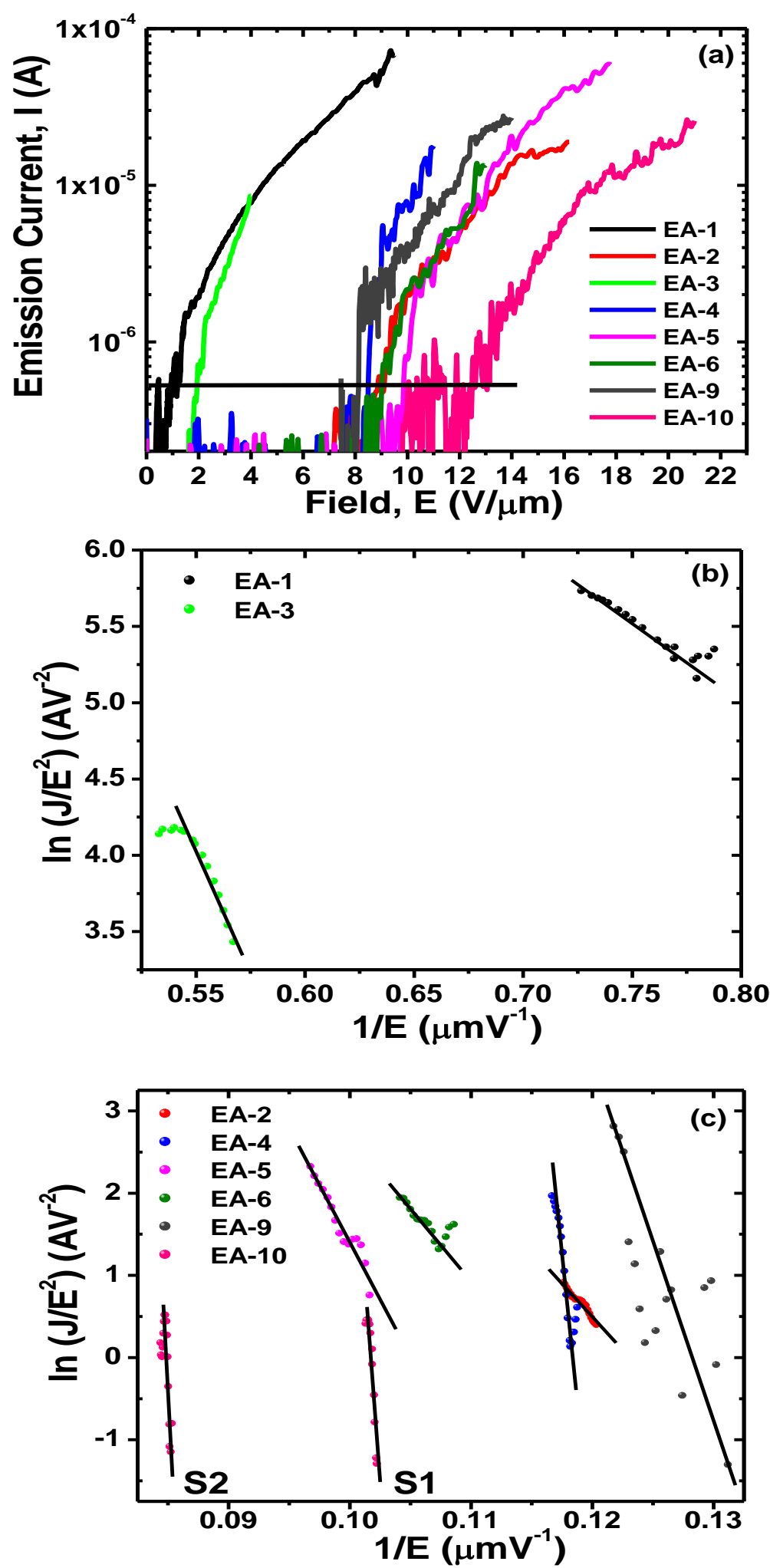

Figure 8 